\title{
PREVALENCE AND PREDICTORS OF DIABETES AMONG ADULTS IN RURAL DHARWAD, INDIA: A CROSS-SECTIONAL STUDY
}

\author{
SHRINIVAS SANGAPPA TAMBOLI*, RAMAMURTHY B \\ Department of Computer Science, Christ (Deemed to be University), Bengaluru - 560029, Karnataka, India. \\ Email: shrinivas.tam500@gmail.com
}

Received: 10 November 2017, Revised and Accepted: 19 January 2018

\begin{abstract}
Objective: Diabetes is a long life chronic non-communicable disease and emerging fast as one of the most serious health problems in developed and developing countries, also influences the risk of developing macrovascular complication including heart disease and stroke which are the leading causes of global death. This study aims to find the potential risk factors associated to diabetes among different community (Government, Private
\end{abstract} employees, and Businessmen) of adults 20 years and above.

Methods: A cross-sectional study followed and conducted door-to-door surveyusing World Health Organization STEP Surveillance (WHO STEPS) questionnaire to collect the information of sociodemographic, anthropometric and behavioral characteristics. Multiple logistic regression is used to determine the risk factors of diabetes among study population. Data was pre-processed and used Chi-square test and t-test to find the comparison between the attributes.

Results: Overall prevalence of diabetes is found to be $49.1 \%$ in which prevalence more in females with $51.7 \%$ than in males with $46.8 \%$, the education, health examination, and waist circumference were found to be the potential risk factors. The total study subjects include 1083 in which male is 611 and female is 472 .

Conclusion: The current study reflects the importance of Diabetes disease among the study population in rural Dharwad and this study can be utilized to control and prevent diabetes. It's an early call for the females of the study population to take care and practice healthy food in day today life and the outcome of the study says that the education should be given prime importance in everyone's life.

Keywords: Diabetes, Prevalence, Risk factors, Pre-Diabetes, Sociodemographic, Anthropometric.

(C) 2018 The Authors. Published by Innovare Academic Sciences Pvt Ltd. This is an open access article under the CC BY license (http://creativecommons. org/licenses/by/4. 0/) DOI: http://dx.doi.org/10.22159/ajpcr.2018.v11i5.23582

\section{INTRODUCTION}

According to the International Diabetes Federation, the global population of 415 million adults have diabetes in 2015, and it is expected to rise 642 million by 2040. It is estimated that one in 11 adults has diabetes in 2015 and expected that one in 10 adults will have diabetes in 2040. In financial relations, the global burden of diabetes is immense, the annual expenditure of 673 billion US dollars in 2015, which constituted $12 \%$ of global health expending for that year. As in urban areas of low- and middle-income countries, the recent prevalence suggests that diabetes an increasing problem and well recognized as public health priority among urban and rural population [1].

India is the second largest diabetes adult population after China and children population with type 1 diabetes next to USA, also the World Health Organization (WHO) has anticipated the supreme growth in the world diabetes in India [2]. According to the International Diabetes Federation, there are 40.9 million people are subjected to diabetes and it is likely to rise to 69.9 million by the year 2025 . India being the second largest individuals living with diabetes, spent $<3 \%$ of the World's total expenditure on diabetes comparing to other top ten diabetes populated countries. It is believed that the Indians have greater degree of insulin resistance and a solid genetic tendency to diabetes, due to swift changes in culture, socioeconomic development, high-tech improvements, and transformation in lifestyle due the Western Culture adoption, behavioral pattern, environmental factors like obesity, physical inactivity, diet (saturated fat and unsaturated fat) and aging population leads to prominent health changeover which is responsible for developing diabetes.

Dasappa et al. has set up a cross-sectional study to determine the "prevalence of diabetes and assessments of their risk factors associated with diabetes and Pre-diabetes in urban slums of Bangalore". The study was conducted among adults of 35 years and above in four urban slums of Bangalore, in which only the selected people were considered, who are residing for past 2 years in the slums. The author did house-to-house survey for gathering data of the eligible people, and, they collected the details such as sociodemographic factors, morbidity profile, and anthropometric measurements. The collected data were entered into Microsoft Excel 2007, and they used Statistical Package for Social Sciences (SPSS) version 19.0 for statistical analysis, they analyzed the data using descriptive statistics for sociodemographic variables, morbidity profile, and risk factor data. In this study, Chi-square test of association or Fisher's exact probability test was used for finding the association between diabetes and associated variables. The variables which have statistically potential association were entered into multiple logistic regression model. This study got the result that, prevalence of diabetes was $12.33 \%$ and of prediabetes was $11.57 \%$ and they showed statistically significant association with prevalence of diabetes and prediabetes factors such as increasing age, over weight and obesity, sedentary lifestyle, tobacco consumption, and diet habits [3].

Okwechime et al. conducted a study to estimate the "prevalence and predictors of pre-diabetes and diabetes among adults 18 years or older in Florida: A multinomial logistic modelling approach". Author collected the data between the period of January and December 2013, were taken from Florida's Behavioral Risk Factor Surveillance System. They performed descriptive analyses to estimate the prevalence of prediabetes and diabetes. Author examined the predictors of prediabetes and diabetes using multinomial logistic regression model. Model goodness-of-fit was gauged using both the multinomial goodness-of-fit test. In this study, author found that based on the final multivariable multinomial model, only being overweight, obese, hypertensive, hypercholesterolemic, and arthritic had significant associations with prediabetes. According to this study outcome, determined the risk of diabetes increased with increasing age, lower income, in males, and with physical inactivity [4]. 
Akter et al., "prevalence of diabetes and prediabetes and their risk factors among Bangladeshi adults: a nationwide survey". Author collected the data samples from the 2011 Bangladesh Demographic and Health Survey using a stratified, multistage, cluster sampling design. Risk factors for diabetes and prediabetes were identified using multilevel logistic regression models, with adjustment for clustering within households and communities. Among the participants, 56.0\% of diabetics were not aware that, they had the condition and only $39.5 \%$ we are taking treatment regularly. The study found that the chance of diabetics between the age 55 and 59 years is nearly double that in those aged 35-39 years, also between richest households and poorest. According to this study, the probability of diabetes was notably associated with educational level, body weight, and the presence of hypertension and almost one in ten adults in Bangladesh was found to have diabetes [5].

Tripathy et al. "prevalence and risk factors of diabetes in a large community-based study In North India: Results from a steps survey in Punjab, India". This study reports on the prevalence of diabetes and prediabetes and data collected by household NCD steps survey and the information like anthropometric and blood pressure measurements were collected using the WHO steps questionnaire. Author performed the statistical analysis such as, Chi-square test was used for comparison of proportions across groups and ANOVA test for comparison of means across groups. Univariate and multiple logistic regression analysis was done to determine the predictors of diabetes. This study results, age group (45-69 years), marital status, hypertension, obesity, and family history of diabetes were found to be the risk factors significantly associated with diabetes [6].

Akhtar and Dhillon "Prevalence of diagnosed diabetes and associated risk factors: Evidence from the large-scale surveys in India." This paper estimates the diabetes prevalence in states and districts of India and inspects the associated risk factors with newly diagnosed and selfreported diabetes. Author collected the information from clinical, anthropometric, and biochemical data from District Level Household and Facility Survey (2012-2013) and Annual Health Survey (2014). Based on the collected information, on glucose level of the blood sample and defines diabetes as per the WHO (1999) criteria. They performed multinomial logistic regression to identify the risk factors of diabetes. The study outcome of their work estimates $7 \%$ adults with diabetes in India and urban have the more diabetes than the rural. Widowed, older persons, and persons with high blood pressure have very high risk of both diagnosed and self-reported diabetes. Author found that Hindus, Muslims, and Christians have higher, and Sikhs have less risk of diabetes and could not find the association of diabetes with some of the key factors such as physical activity levels, dietary habits, occupation status, expenditure on treatments, and family history as information was not available in the data [7].

Considering the background, the diabetes is increasing rapidly and according to the statistics it is predicted to be a significant difference in the population that leads to a problem in economic as well as in the development of the nation, so the changing epidemiology of diabetes in India is required. It is essential to consider the present conditions and analyze, to battle in guiding against the current scenario. Hence, the present study is conducted to determine the prevalence and finding the risk factors associated with diabetes among the government, private employees, and businessmen. The outcomes of this study will be important to know the health conditions among the government, private employees, and businessmen, and for informing public health program decisions.

\section{METHODS}

\section{Materials}

The data are collected through house-to house survey with help of WHO STEPS questionnaire in this area, out of total population our examination considered just for the residents who are living for past 2 years and who has current occupation as government, private workers, and individuals having their businesses. These residents considered to be as qualified participants and three visits made to each of the houses, if in the last visit the participants were not available and refused to take part in the examination, they are considered to be nonresponder, also in our study pregnant women are ignored in the total study population.

\section{Methods}

Study design

This study is a cross-sectional, community-based among adults whose age is 20 years and above who were residents of Kelgeri, Dharwad district, Karnataka state, India, total study population accounts 1083 in which male is 611 and female is 472 according to the census of 2011 [8].

\section{Study instrument}

The data gathered by means of the WHO STEPS questionnaire [9] was used with minor alterations. The questionnaire was created in English language and was figured out how to regulate in Kannada (the local language) to the participants, the questionnaire was designed to gather information like sociodemography attributes, medical related inquiries, measurements, and behavioral information on smoke and alcohol use, fruit and vegetable intake, physical activity (exercise), family history of diabetes conditions, health examination and physical measurements such as height, weight, blood pressure, and waist circumference. Biochemical tests conducted to measure fasting blood glucose were collected in WHO steps strategy. During the collection of information through WHO steps questionnaire, the eligible residents were completely informed with respect to the reason for the examination so that the participants trust and confidently gave their details for our study.

Data were gathered with the help of a two-membered team (1 researcher, 1 medical investigator). The participants were considered as tobacco user if they smoke cigarettes ( 1 or more in 3 days) and as alcohol consumer if they consume then, marked in terms of consumption period such as daily, weekly, and monthly. In case of vegetable and fruit consumptions, the intake of fruit might be either raw or juice, then the consumption measured into two categories (Every day, twice a week) and about the physical activity information it is based on the time spent on exercise or work done in either work time or leisure time of $30 \mathrm{~min}$ daily then the person considered to be active. If the participant's family members such as aunt, uncle, parents, brother, sister, grandparents, and first cousin then considered as the positive family history of the diabetes.

The blood glucose was measured using the blood glucose measurement device (Freestyle Optimum H Glucometer) and diabetic participants were ignored in this test and considered as positive. Blood pressure was measured in a sitting position with the help of the standard measuring instrument. Twice blood pressure has been measured with the interval of 5 min the mean of both the measurements is taken into consideration for the study. Health examination which is recorded based on the health check-up related to blood sugar, blood pressure, and other for past 1 year. Height was verified using the measuring tape in centimeters, participants were informed before measuring to stand straight, without shoes with their back against the wall, heels together and looking forward. Weight is measured using the standard digital weighing scale, and weight value is recorded in kilograms.

Waist circumference is measured using the non-stretchable measuring tape; the value is recorded in centimeters. Body mass index (BMI) was calculated using the formula, weight $(\mathrm{kg}) / \mathrm{height}\left(\mathrm{m}^{2}\right)$, participants considered to be obese if BMI $\geq 25 \mathrm{~kg} / \mathrm{m}^{2}$ and overweight when BMI $\geq 23 \mathrm{~kg} / \mathrm{m}^{2}$, abdominal obesity was considered to be present when waist circumference $\geq 90 \mathrm{~cm}$ in males and $\geq 80 \mathrm{~cm}$ in females. Education of the participants are recorded based on their qualification (Undergraduate, Postgraduate, $12^{\text {th }}, 10^{\text {th }}$ ), and age is verified using the date of birth of the participants. After the entire examination process, an overview of the 
diabetes disease, complication, symptoms, and treatment process were conveyed to the participants.

\section{Statistical methods}

Collected data were manually entered in Microsoft Excel 2016 and statistical analysis was done in SPSS version 21.0. The categorical attributes are reviewed using the proportions and the continuous attributes with the mean or median, whichever is appropriate, with 95\% confidence intervals. The relationship between these attributes proportions is computed using Chi-square test for across groups and t-test for comparison of means across group. To determine the potential predictors of diabetes, univariate and multiple logistic regression analysis performed. In the univariate analysis, the attributes inputted into multiple regression models were chosen based on significance $(\mathrm{p}<0.05)$.

\section{RESULTS}

Out of the total study population of 1083 residents, the male and female participants were 299 (males=156 and females=143), some of them were not eligible and non-responders. The sociodemography and behavioral information characteristics of the study participants are as shown in Table 1. Most of the respondents lies in the age group (40-59) with $47.8 \%$, and overall male participants were more in numbers (52.2\%). Of total study population, $43.1 \%$ were primary educated and $36.5 \%$ were private employees, also non-smokers and non-alcoholic were $70.2 \%$ and $68.9 \%$. Participants who do daily exercise and consume vegetable and fruits were $53.5 \%$ and $56.5 \%$, and participants with obesity and hypertension were $59.6 \%$ and $16.7 \%$, as of occupation government, private employee, and businessmen were $36.1 \%, 36.5 \%$, and 27.4 .

Table 2 outlines, the total prevalence of diabetes among the study respondents was found to be $49.1 \%$ (95\% CI 0.433-0.545) which was higher among the private employee $49.5 \%$ (95\%, CI 0.398-0.593) compared to other occupations. Male participants with $46.8 \%$ (95\%, CI 0.388-0.549) were found to have diabetes compared to female with $51.7 \%$ (95\%, CI $0.432-0.602$ ), similarly the age group of $40-59$ with $55.2 \%$ (95\%, CI $0.467-0.636$ ) has the highest prevalence of diabetes among the other age group. In the family history of diabetes comparing to other family member's brother and sister has highest prevalence of diabetes with $60.0 \%$ (95\%, CI $0.452-0.736)$ and as of the vegetables and fruit intake, participants consume every day with a prevalence of $59.9 \%$ (95\%, CI $0.431-0.586)$ and as of obesity with $50.0 \%$ (95\%, CI $0.410-0.590)$. With $50.0 \%(95 \%$, CI $0.430-0.570)$ were non-smoker and non-alcoholic were $50.5 \%$ (95\%, CI 0.435-0.575).

Table 3 describes the predictors of the diabetes, on using binary logistic regression, the prevalence of diabetes shown the highest significant among those who are completed their education till primary and secondary, also those who are positively marked in health examination and the participants whose has waist circumference above normal. There was no statistical significant among the other characteristics in the study such as age, gender, bmi, alcohol, smoke, vegetable and fruit intake, family history of diabetes, hypertension, occupation and daily exercise but education, health examination, and waist circumference found to statistically significant $(\mathrm{p}<0.05)$

\section{DISCUSSION}

This study found $49.1 \%$ overall prevalence rate of diabetes, which is higher when compared to few other similar studies on the prevalence of diabetes. Females participants has the highest prevalence than the male participants $[10,11]$ whereas in other studies, male subjects have the higher prevalence rate $[12,13]$ and considering the prevalence rate of diabetes among the study participants who fall in age group 20-39 has less chance of getting diabetes than whose age is above 40 years, which is like some other studies $[14,15]$

This study considered only private, government employees, and businessmen as the occupation in which among these businessmen has
Table 1: Sociodemography and behavioral information characteristics of adults in rural Dharwad, India

\begin{tabular}{|c|c|c|}
\hline S. No. & Characteristics & $\mathrm{n}=299(\%)$ \\
\hline \multirow[t]{4}{*}{1} & Age & \\
\hline & 20-39 & $129(43.1)$ \\
\hline & $40-59$ & $143(47.8)$ \\
\hline & $60+$ & $27(9.1)$ \\
\hline \multirow[t]{3}{*}{2} & Gender & \\
\hline & Male & $156(52.2)$ \\
\hline & Female & $143(47.2)$ \\
\hline \multirow[t]{4}{*}{3} & Education & \\
\hline & Primary & $129(43.1)$ \\
\hline & Secondary & $110(36.8)$ \\
\hline & Higher & $60(20.1)$ \\
\hline \multirow[t]{4}{*}{4} & Occupation & \\
\hline & Government employee & $108(36.1)$ \\
\hline & Private employee & $109(36.5)$ \\
\hline & Own business & $82(27.4)$ \\
\hline \multirow[t]{3}{*}{5} & Health examination & \\
\hline & Yes & 65 (21.7) \\
\hline & No & $234(78.3)$ \\
\hline \multirow[t]{6}{*}{6} & Family history of diabetes & \\
\hline & No & $139(46.5)$ \\
\hline & Parents & $53(17.7)$ \\
\hline & Brother and sister & $50(16.7)$ \\
\hline & Grandparents & $16(5.4)$ \\
\hline & Other & $41(13.7)$ \\
\hline \multirow[t]{3}{*}{7} & Daily exercise (30 min) & \\
\hline & Yes & $160(53.5)$ \\
\hline & No & $139(46.5)$ \\
\hline \multirow[t]{4}{*}{8} & Vegetable and fruit intake & \\
\hline & Everyday & $169(56.5)$ \\
\hline & Weekly & $50(16.7)$ \\
\hline & Twice a week & $80(26.8)$ \\
\hline \multirow[t]{3}{*}{9} & Smoke & \\
\hline & Yes & $89(29.8)$ \\
\hline & No & $210(70.2)$ \\
\hline \multirow[t]{5}{*}{10} & Alcohol & \\
\hline & No & $206(68.9)$ \\
\hline & Daily & $23(7.7)$ \\
\hline & Weekly & 49 (16.7) \\
\hline & Monthly & $21(7.0)$ \\
\hline \multirow[t]{3}{*}{11} & BMI & \\
\hline & $<25$ (Normal) & $126(40.4)$ \\
\hline & $>25$ (Obesity) & $173(59.6)$ \\
\hline \multirow[t]{4}{*}{12} & Waist circumference & \\
\hline & $<31$ inch and<34 & $121(40.4)$ \\
\hline & inch (normal) & \\
\hline & $<31$ inch and $<34$ & $178(59.6)$ \\
\hline \multirow[t]{3}{*}{13} & $\begin{array}{l}\text { Inch (obesity) } \\
\text { Hypertension* }\end{array}$ & \\
\hline & Yes & $50(16.7)$ \\
\hline & No & $249(83.3)$ \\
\hline
\end{tabular}

*Systolic blood pressure $>140$ and diastolic blood pressure $>90$, BMI: Body Mass Index (Kilogram/metre ${ }^{2}$ )

the high prevalence rate but in others work occupation is considered in different dimensions such as housewife, farmer, and teacher, so on [16]. In a study from A. Ramachandran et al. diabetes in India, the family history of diabetes has the high prevalence rate when it is considered as positive [17], whereas in our study the positive output is framed in terms of distinct categories such as parents, grandparents, brother, and sister and other, similar to their study even we got the high prevalence rate among the study participants who is positive in the family history of diabetes.

When it comes to the characteristics such as smoke and alcohol our study shows the high prevalence rate in alcoholics and non-smoker, similarly in others works they found that non-smoker have the high prevalence. The current study we found the participants who has BMI $>25$ (obesity) and hypertension has the high prevalence rate when compared to other 
Table 2: Prevalence of diabetes in rural Dharwad, India, 2016-2017. N=299.

\begin{tabular}{|c|c|c|c|c|}
\hline S. No. & Characteristics & $\mathbf{N}$ & Prevalence (\%) & CI (95\%) \\
\hline \multirow[t]{4}{*}{1} & Age & & & \\
\hline & $20-39$ & 59 & 45.7 & $0.369-0.547$ \\
\hline & $40-59$ & 79 & 55.2 & $0.467-0.636$ \\
\hline & $60+$ & 9 & 33.3 & $0.165-0.540$ \\
\hline \multirow[t]{3}{*}{2} & Gender & & & \\
\hline & Male & 73 & 46.8 & $0.388-0.549$ \\
\hline & Female & 74 & 51.7 & $0.432-0.602$ \\
\hline \multirow[t]{4}{*}{3} & Education & & & \\
\hline & Primary & 77 & 59.7 & $0.507-0.682$ \\
\hline & Secondary & 48 & 43.6 & $0.342-0.534$ \\
\hline & Higher & 22 & 36.7 & $0.246-0.501$ \\
\hline \multirow[t]{4}{*}{4} & Occupation & & & \\
\hline & Government Employee & 53 & 49.1 & $0.393-0.589$ \\
\hline & Private Employee & 54 & 49.5 & $0.398-0.593$ \\
\hline & Own Business & 40 & 48.8 & $0.376-0.601$ \\
\hline \multirow[t]{3}{*}{5} & Health Examination & & & \\
\hline & Yes & 40 & 61.5 & $0.486-0.733$ \\
\hline & No & 107 & 45.7 & $0.392-0.523$ \\
\hline \multirow[t]{6}{*}{6} & Family history of diabetes & & & \\
\hline & No & 70 & 50.4 & $0.418-0.589$ \\
\hline & Parents & 20 & 37.7 & $0.248-0.521$ \\
\hline & Brother and sister & 30 & 60.0 & $0.452-0.736$ \\
\hline & Grandparents & 6 & 37.5 & $0.152-0.646$ \\
\hline & Other & 21 & 51.2 & $0.351-0.621$ \\
\hline \multirow[t]{3}{*}{7} & Daily exercise (30 min) & & & \\
\hline & Yes & 82 & 51.2 & $0.432-0.592$ \\
\hline & No & 65 & 46.8 & $0.383-0.554$ \\
\hline \multirow[t]{4}{*}{8} & Vegetable and fruit intake & & & \\
\hline & Everyday & 86 & 50.9 & $0.431-0.586$ \\
\hline & Weekly & 22 & 44.0 & $0.300-0.587$ \\
\hline & Twice a week & 39 & 48.7 & $0.374-0.602$ \\
\hline \multirow[t]{3}{*}{9} & Smoke & & & \\
\hline & Yes & 42 & 47.2 & $0.365-0.581$ \\
\hline & No & 105 & 50.0 & $0.430-0.570$ \\
\hline \multirow[t]{5}{*}{10} & Alcohol & & & \\
\hline & No & 104 & 50.5 & $0.435-0.575$ \\
\hline & Daily & 13 & 56.5 & $0.345-0.768$ \\
\hline & Weekly & 20 & 40.8 & $0.270-0.558$ \\
\hline & Monthly & 10 & 47.6 & $0.257-0.702$ \\
\hline \multirow[t]{3}{*}{11} & BMI & & & \\
\hline & $<25$ (normal) & 84 & 48.6 & $0.409-0.563$ \\
\hline & $>25$ (obesity) & 63 & 50.0 & $0.410-0.590$ \\
\hline \multirow[t]{3}{*}{12} & Hypertension* & & & \\
\hline & Yes & 25 & 50.0 & $0.355-0.645$ \\
\hline & No & 122 & 49.0 & $0.426-0.554$ \\
\hline
\end{tabular}

Diabetes is defined as individuals diagnosed those who had fasting blood glucose $\geq 126 \mathrm{mg} / \mathrm{dl}(\geq 7 \mathrm{mmol} / \mathrm{l})$. Systolic Blood Pressure $>140$ and Diastolic Blood

Pressure>90, CI: Confidence Interval, BMI: Body Mass Index $\left(\mathrm{Kg} / \mathrm{m}^{2}\right)$

normal participants in the study, similarly in some studies positive hypertension and BMI $>25$ (obesity) are considered high prevalence rate of diabetes [18]. This study found education, health examination, and waist circumference as the potential predictors of the diabetes in rural Dharwad, India whereas likely potential characteristics such as BMI, daily exercise (30 $\mathrm{min}$ ), age, and family history of diabetes where not statistically significant in this study outcome.

Tripathy et al. in a large community-based study in North-Punjab, they found Age group (45-69 years), marital status, hypertension, obesity, and family history of diabetes mellitus as their risk factors of diabetes and in our study majority participants were educated primary and secondary, but less participants who completed higher education, primary educated participants have the higher prevalence rate among the other two but in another study shown that secondary educated subjects have more prevalence rate [6]. In another work from, Khwaja Mir Islam Saeed et al. a study among Kabul, Afghanistan, they found education as the statistical significant, which is one of the risk factors of diabetes among the Kabul citizens [19]. The present study we determined an interesting statistical significant risk factor of diabetes that is health examination which is recorded based on the health checkup of blood sugar and blood pressure for past 1 year.

In this study, due to the high waist circumference, the participants are considered to have obesity and of also it influences to get affected by the diabetes disease, as well as it is the potential risk factor the diabetes, similarly several other studies have reported that waist circumference as the potential risk factor in their work [20]. Meng et al. in which three data mining models have been applied and reported education as the potential risk factor along with other risk factors in their study [21], similarly in the current study, we found primary and secondary level education were highly statistical significant risk factor of diabetes among all other characteristics.

One of the major surveillances of our study is the risk factors of diabetes only those who has the occupation as government, private employees, and businessmen, so that the awareness of the diabetes among these are reached and examining all other factors of the participants it is an early call to avoid the diabetes. The strength of the study is, the data collected using the STEPS questionnaire, and limitation of the study is the measurement of blood glucose was done using glucometer instead 
Table 3: Binary logistic regression to explore the predictors of diabetes among adults in rural Dharwad, India.

\begin{tabular}{|c|c|c|c|c|c|c|}
\hline S. No. & Characteristics & Total & Diabetes & Odd Ratio & CI $(95 \%)$ & p value \\
\hline \multirow[t]{4}{*}{1} & Age & & & 1.083 & $0.692-1.697$ & 0.726 \\
\hline & $20-39$ & 129 & $59(45.7)$ & - & - & - \\
\hline & $40-59$ & 143 & $79(55.2)$ & - & - & - \\
\hline & $60+$ & 27 & $9(33.3)$ & - & - & - \\
\hline \multirow[t]{3}{*}{2} & Gender & & & 0.709 & $0.394-1.275$ & 0.251 \\
\hline & Male & 156 & $73(46.8)$ & - & - & - \\
\hline & Female & 143 & $74(51.7)$ & - & - & - \\
\hline \multirow[t]{4}{*}{3} & Education & & & & & \\
\hline & Primary & 129 & 77 (59.7) & 2.667 & $1.432-4.969$ & $0.002 *$ \\
\hline & Secondary & 110 & $48(43.6)$ & 4.323 & $1.988-9.400$ & $0.000 *$ \\
\hline & Higher & 60 & $22(36.7)$ & - & - & - \\
\hline \multirow[t]{4}{*}{4} & Occupation & & & & & \\
\hline & Government Employee & 108 & $53(49.1)$ & 0.686 & $0.365-1.288$ & 0.241 \\
\hline & Private Employee & 109 & $54(49.5)$ & 1.039 & $0.541-1.993$ & 0.909 \\
\hline & Own Business & 82 & $40(48.8)$ & - & - & - \\
\hline \multirow[t]{3}{*}{5} & Health Examination & & & & & \\
\hline & Yes & 65 & $40(61.5)$ & 1.878 & $1.001-3.524$ & $0.050 *$ \\
\hline & No & 234 & $107(45.7)$ & - & - & - \\
\hline \multirow[t]{6}{*}{6} & Family history of diabetes & & & & & \\
\hline & No & 139 & $70(50.4)$ & 1.870 & $0.902-3.875$ & 0.092 \\
\hline & Parents & 53 & $20(37.7)$ & 0.660 & $0.323-1.346$ & 0.253 \\
\hline & Brother and sister & 50 & $30(60.0)$ & 1.937 & $0.613-6.123$ & 0.260 \\
\hline & Grandparents & 16 & $6(37.5)$ & 0.936 & $0.442-1.983$ & 0.863 \\
\hline & Other & 41 & $21(51.2)$ & - & - & - \\
\hline \multirow[t]{3}{*}{7} & Daily Exercise (30 min) & & & & & \\
\hline & Yes & 160 & $82(51.2)$ & 1.547 & $0.861-2.780$ & 0.145 \\
\hline & No & 139 & $65(46.8)$ & - & - & - \\
\hline \multirow[t]{4}{*}{8} & Vegetable and Fruit Intake & & & & & \\
\hline & Everyday & 169 & $86(50.9)$ & 1.537 & $0.759-3.112$ & 0.232 \\
\hline & Weekly & 50 & $22(44.0)$ & 1.387 & $0.757-2.538$ & 0.289 \\
\hline & Twice a week & 80 & 39 (48.7) & - & - & - \\
\hline \multirow[t]{3}{*}{9} & Smoke & & & & & \\
\hline & Yes & 89 & $42(47.2)$ & 0.728 & $0.387-1.369$ & 0.324 \\
\hline & No & 210 & $105(50.0)$ & & & \\
\hline \multirow[t]{5}{*}{10} & Alcohol & & & & & \\
\hline & No & 206 & $104(50.5)$ & 0.688 & $0.262-1.806$ & 0.447 \\
\hline & Daily & 23 & $13(56.5)$ & 1.022 & $0.477-2.190$ & 0.956 \\
\hline & Weekly & 49 & $20(40.8)$ & 1.265 & $0.442-3.619$ & 0.661 \\
\hline & Monthly & 21 & $10(47.6)$ & - & - & - \\
\hline \multirow[t]{3}{*}{11} & BMI & & & & & \\
\hline & $<25$ (normal) & 126 & $84(48.6)$ & 0.963 & $0.581-1.597$ & 0.884 \\
\hline & $>25$ (obesity) & 173 & $63(50.0)$ & - & - & - \\
\hline \multirow[t]{3}{*}{12} & Hypertension $* *$ & & & & & \\
\hline & Yes & 50 & $25(50.0)$ & 0.656 & $0.322-1.338$ & 0.247 \\
\hline & No & 249 & $122(49.0)$ & - & - & - \\
\hline \multirow[t]{3}{*}{13} & Waist circumference ${ }^{* * *}$ & & & & & \\
\hline & $<31$ inch and $<34$ inch & 49 & $19(38.7)$ & - & - & - \\
\hline & $<31$ inch and $<34$ inch & 250 & $128(51.2)$ & 2,166 & $1.076-4.360$ & $0.030^{*}$ \\
\hline
\end{tabular}

${ }^{*}$ p value $<0.05$ is considered as statistically significant, ${ }^{* *}$ systolic blood pressure $>140$ and diastolic blood pressure $>90, * * * \geq 34$ inch for males and $\geq 31$ inch for females, CI: Confidence interval, BMI: Body Mass index $\left(\mathrm{Kg} / \mathrm{m}^{2}\right)$

of venous blood glucose estimation, also was unable to collect large data of above 60-year age group and information about the smoke and alcohol participants were hesitated to give frank answers.

\section{CONCLUSION}

The current study reflects the importance of diabetes disease among the study population in rural Dharwad, India, and it is an alarm for the government, private employees, and businessmen to stay away from the diabetes disease. Among the overall study population, $49.1 \%$ was found to have prevalence of diabetes which requires a critical consideration. At last, this study can be utilized to figure well-being approaches and procedures for suitable control and prevention of diabetes in rural Dharwad population.

\section{REFERENCES}

1. International Diabetes Federation. IDF Diabetic Atlas. $7^{\text {th }}$ ed. Available from: http://www.idf.org/idf-diabetes-atlas, seventh-edition. [Last accessed on 2016 Aug 30].
2. Hwang CK, Han PV, Zabetian A, Ali MK, Narayan KM. Rural diabetes prevalence quintuples over twenty-five years in low-and middleincome countries: A systematic review and meta-analysis. Diabetes Res Clin Pract 2012;96:271-85

3. Dasappa H, Fathima FN, Prabhakar R, Sarin S. Prevalence of diabetes and pre-diabetes and assessments of their risk factors in urban slums of Bangalore. J Fam Med Primary Care 2015;4:399-404.

4. Okwechime IO, Roberson S, Odoi A. Prevalence and predictors of pre-diabetes and diabetes among adults 18 years or older in Florida: A Multinomial logistic modelling approach. PLoS One 2015; 10:e0145781.

5. Akter S, Rahman MM, Abe SK, Sultana P. Prevalence of diabetes and prediabetes and their risk factors among Bangladeshi adults: A nationwide survey. Bull World Health Organ 2014;92:204-13, 213A.

6. Tripathy JP, Thakur JS, Jeet G, Chawla S, Jain S, Pal A, et al. Prevalence and risk factors of diabetes in a large community-based study in North India: Results from a steps survey in Punjab, India. Biomed Central 2017;9:8.

7. Akhtar SN, Dhillon P. Prevalence of diagnosed diabetes and associated 
risk factors: Evidence from the large-scale surveys in India. J Soc Health Diabetes 2017;5:28-36.

8. Available from: http://www.census2011.co.in/data/village/602272kelgeri-karnataka.html.

9. Available from: http://www.who.int/chp/steps/STEPS_Instrument_ v2.1.pdf.

10. Qamar M, Rashid R, Ahmad S, Shaikh FA, Ismail NE. Awareness of diabetes mellitus among general public in Shah Alam, Malaysia: A cross-sectional study. Asian J Pharm Clin Res 2017;10:192-6. Available from: https:/www.innovareacademics.in/journals/index.php/ ajpcr/article/view/17747.

11. Arafat M, Salam A, Arafat O. The association of Type 2 diabetes with obesity and other factors: In multinational community. Int J Pharm Pharm Sci 2014;6:257-60. Available from: http://www.innovareacademics.in/ journals/index.php/ijpps/article/view/2179/1230.

12. Shah A, Afzal M. Prevalence of diabetes and hypertension and association with various risk factors among different Muslim populations of Manipur, India. J Diabetes Metabol Disord 2013;12:52.

13. Valliyot B, Sreedharan J, Muttappallymyalil J, Valliyot SB. Risk factors of Type 2 diabetes mellitus in the rural population of North Kerala, India: A case control study. Diabetol Croatica 2013;42:1-41

14. Zia A, Bhatti A, Wang FJ, John P, Kiani AK, Zafar J, et al. Prevalence of Type 2 diabetes-associated complications in Pakistan. Int J Diabetes
Dev Ctries 2015;36:179-88.

15. Rao CR. A study on the prevalence of Type 2 diabetes in coastal Karnataka. Int J Diabetes Dev Ctries 2010;30:80-5.

16. Narayanamurthy MR, Baghel RK, Siddalingappa H. Prevalence and factors influencing Type 2 diabetes mellitus in rural Mysore. Int J Diabetes Dev Ctries 2014;35:75-8.

17. Ramachandran A, Snehalatha C, Kapur A, Vijay V, Mohan V, Das AK, et al. High prevalence of diabetes and impaired glucose tolerance in india: National urban diabetes survey. Diabetologia 2001;44:1094-101.

18. Ebrahimi H, Emamian MH, Shariati M, Hashemi H, Fotouh A. Diabetes mellitus and its risk factors among a middle-aged population of Iran, a population-based study. Int J Diabetes Dev Ctries 2015;36:189-96.

19. Saeed KM, Asghar RJ, Ansar MN. Prevalence and risk factors associated with diabetes mellitus among Kabul citizens-Afghanistan 2012. Int J Diabetes Dev Ctries 2015. DOI: 10.1007/s13410-014-0270-3.

20. Patil RS, Gothankar JS. Assessment of risk of Type 2 diabetes using the Indian diabetes risk score in an urban slum of Pune, Maharashtra, India: A cross-sectional study. WHO South East Asia J Public Health 2016;5:53-61.

21. Meng XH, Huang YX, Rao DP, Zhang Q, Liu Q. Comparison of three data mining models for predicting diabetes or prediabetes by risk factors. Kaohsiung J Med Sci 2013;29:93-9. 